\title{
Scoping Review of the Core Elements of Technical Assistance Models and Frameworks
}

\author{
Carl J. Dunst ${ }^{1, *}$, Kimberly Annas ${ }^{1}$, Helen Wilkie ${ }^{1} \&$ Deborah W. Hamby ${ }^{1}$ \\ ${ }^{1}$ Orelena Hawks Puckett Institute, 128 South Sterling Street, Morganton 28655, North Carolina, USA \\ *Correspondence: Orelena Hawks Puckett Institute, 128 South Sterling Street, Morganton 28655, North Carolina, \\ USA. E-mail: cdunst@puckett.org
}

Received: March 6, 2019 Accepted: April 5, $2019 \quad$ Online Published: April 20, 2019

doi:10.5430/wje.v9n2p109 URL: https://doi.org/10.5430/wje.v9n2p109

\begin{abstract}
A review of 25 technical assistance models and frameworks was conducted to identify the core elements of technical assistance practices. The focus of analysis was on generally agreed upon technical assistance practices that were considered essential for planning, implementing and evaluating the effectiveness of technical assistance. Results indicated that there are five major components of technical assistance and 25 different core elements. Analyses of the models and components found considerable variability within and between components in terms of the core elements that are considered most important or essential. Findings were used to define and describe the core elements of the technical assistance models and frameworks and how they can be used in research and evaluation studies to determine if the use of the core elements and practices are related to changes or improvements in program, organizational, or systems practices.
\end{abstract}

Keywords: technical assistance, models and frameworks, core elements, implications for research

\section{Introduction}

The term technical assistance is used widely in many different fields for describing the types of information sharing, expertise, instruction, training, and other supports for improving program, organization, or system capacity to achieve specific goals, objectives, or outcomes (Fixsen \& Blase, 2009; Friesen, Fetterman, Barclay, \& Burns, 2017; Gutin, Amico, \& Hunguana, 2017; McInerney \& Hamilton, 2007). One of the few dictionary definitions of technical assistance refers to the practice only in terms of advice and training pertaining to equipment installation and maintenance (Free Dictionary, 2018). Attempts to locate definitions or descriptions of the term in the published literature is hampered by the fact that technical assistance is not a controlled vocabulary term in the Educational Resource Information Center (ERIC) thesaurus, APA Thesaurus of Psychological Index Terms, or ProQuest thesaurus. The term is included in the MEDLINE Medical Subject Heading thesaurus but only in terms of health planning technical assistance.

A number of experts have noted the absence of an operational definition of technical assistance in the published and unpublished literature. Blasé (2009) stated that "There is no generic dictionary definition of technical assistance (TA) nor are there commonly adopted definitions of TA in education or special education" (pp. 1-2, emphasis added). The same is the case in other fields and disciplines (e.g., Godfrey et al., 2002; West, Clapp, Davidson Averill, \& Cates, 2012). West et al. (2012), for example, concluded, based on a literature search for a definition of technical assistance, that "We were unable to find a commonly accepted definition of TA in the published literature" (p. 916).

In the absence of a description or operational definition of TA, authors have either proposed working definitions of TA (e.g., West et al., 2012) or have borrowed concepts from related fields to define TA (e.g., Olson, 2018; Ray, Wilson, Wandersman, Meyers, \& Katz, 2012). The one concept most often described as a key element of TA is capacity building (e.g., Hunter et al., 2009; Yousafzai et al., 2014) or capacity development (e.g., Sugai, Simonsen, Freeman, \& La Salle, 2016). West et al. (2012), for example, defined TA as "A dynamic, capacity-building process for designing or improving the quality, effectiveness, and efficiency of specific programmes, research, services, products, or systems" (pp. 916-917). 


\subsection{Technical Assistance Core Elements}

A working or operational definition, however, is only a first step toward understanding the "make-up" of TA. A second and necessary step is describing or specifying the core elements or key practices of TA. This led us to conduct an extensive literature search for reviews or syntheses of the core elements or practices of TA models or frameworks. We were, however, unable to locate any reviews or syntheses of TA models or frameworks but did locate a number of reviews of related practices (Bertram, Suter, Bruns, \& O'Rourke, 2011; Chapman \& Moore, 2010; Hodge \& Turner, 2016; Leeman et al., 2017; Paulsell, Del Grosso, \& Supplee, 2014; Wandersman, Chien, \& Katz, 2012).

Two reviews in particular proved particularly informative in terms of the present scoping review (Katz \& Wandersman, 2016; Meyers, Durlak, \& Wandersman, 2012). Meyers et al. (2012) reviewed the literature with a focus on identifying the critical steps or actions for fostering high quality implementation of a "specific set of [TA] activities to put into practice an activity or program of known dimensions" (Fixsen, Naoom, Blase, Friedman, \& Wallace, 2005, p. 5). Katz and Wandersman (2016) reviewed more than 100 research studies where investigators purported to have used TA to promote adoption and use of evidence-based prevention practices. The focus of their review was the particular TA practices that were used in studies of the effectiveness of interventions to affect changes in outcomes of interest. These investigators however concluded that "there is little consensus about the essential features of TA and how to provide TA with quality....[Our] results indicated that an explicit model or organizing framework is rarely used to plan, implement, and/or evaluate TA" (Katz \& Wandersman, 2016, p. 417).

\subsection{Purpose of the Review}

The purpose of the scoping review described in this paper was to identify the core elements of TA models and frameworks in order to identify the practices considered essential for planning, implementing, and evaluating TA. We searched the published and unpublished literature for TA models and frameworks with a focus on sufficiently detailed descriptions of the core elements of TA in education, human services, health care, and related fields. A scoping review is a broad-brushed mapping of the literature on a particular topic (e.g., TA) that aims to identify common themes or approaches to defining or describing the topic of interest (Pham et al., 2014; Tricco et al., 2016). Our review focused on identifying those core elements of TA that are generally considered the practices that make-up TA models and frameworks. The review was considered a first step in identifying which core elements are considered most important in terms of the intended outcomes of TA found in studies and evaluations of the use of TA to affect program, organization, or system change.

Our review was informed by lessons learned in Katz and Wandersman (2016) and Meyers et al. (2012) in terms of the make-up of TA for informing program and organizational quality improvement. The scoping review differed however from these two reviews in several important ways. First, we were primarily interested in identifying the core features of TA models and frameworks that proponents claim are the key practices of TA. Second, we focused on models and frameworks that emphasized practices involving program, organizational, and system change in education, human services, and related fields (health care, pregnancy prevention, etc.). Our primary interest was the core elements of TA that could be used to inform improvements in and the effectiveness of program, organization, or system change to the extent that the core elements were subsequently found to be associated with intended outcomes or benefits. The findings from the review were expected to inform the analysis of studies and evaluations of TA to improve program, organizational, and system-level change practices in order to identify evidence-based core elements.

\section{Method}

\subsection{Search Strategy}

TA models and frameworks were located through searches of ERIC, PsycInfo, ProQuest Central, MEDLINE, Google Scholar, Google, and other electronic sources and databases. These were supplemented by searches of the reference sections or bibliographies in all located papers and reports. No limitations were placed on the year of the located papers or type of report (published, unpublished, briefs, conference presentations, etc.).

The searches were conducted using the search terms "technical assistance" AND "model OR framework." Separate searches were conducted in all of the above referenced electronic databases using either quotation marks or parentheses around the search terms depending on the database. Results were sorted by relevance and copies of all papers, reports, documents, etc. retrieved until no new sources were found which included sufficiently detailed descriptions of TA models or frameworks. 


\subsection{Inclusion Criteria}

Papers and other documents were retained for analysis if there was a description of the make-up of TA or there was a graphical depiction of a TA model or framework. The goal was not an exhaustive list of TA models or frameworks but rather a representative sampling of models or frameworks in education, human services, and related fields.

Papers and documents were excluded if they did not include any description, a reference to, or graphical representation of the make-up of TA; even if the authors stated that their papers or documents included a description of a TA model or framework. The largest number of retrieved papers and other documents that included TA model or framework in the titles, abstracts, or bodies of the reports did not, in fact, include descriptions of the core elements of TA and were excluded from further analysis.

\subsection{Method of Analysis}

The Katz and Wandersman (2016) and Meyers et al. (2012) papers were used to initially identify different TA tasks, activities, and practices, and to develop a structured coding form for three of the authors to independently review all located papers and reports. The preliminary list of tasks and activities was adapted and changed through an iterative process in order to identify the TA tasks and practices (core elements) of each of the located TA models and frameworks. This entailed a detailed analysis of each paper and report to identify the make-up of the TA models and frameworks (tasks, activities, and practices) and the core elements for each TA model or framework component.

A four-step data coding and analysis process was used to identify and define/describe the core elements of TA models and frameworks. First, 3 of the 4 authors used the structured coding form to independently review each candidate paper and report to identify the make-up of TA of each model and framework. After all the models and frameworks were coded by each author, the information for the core elements was combined and any disagreements resolved through discussions and by each author pointing out where core elements were described in the papers or reports. Second, we searched the PDF or Word versions of all retrieved TA papers and reports using the structured coding form terms as well as related terms to be assured no core elements were missed. Third, we used the information identified in steps one and two to define or describe each core element of the different TA models and frameworks. Fourth, we determined how many TA models and frameworks included each of the core elements by computing the number and percent of the TA models or frameworks that included each core element. The procedure was similar to that used by Katz and Wandersman (2016) for coding and analyzing the presence of different TA elements and features (frames in the investigators' paper) in research studies using TA practices to evaluate the effectiveness of prevention interventions.

\subsection{Inter-Rater Agreement}

Twelve (48\%) of the TA models and frameworks were randomly selected for calculating inter-rater agreement. Agreement was computed as the number of core elements that were rated the same divided by the number of agreements plus nonagreements. The median inter-rater agreement was $94 \%$ (Mean $=94 \%$, Range $=88 \%$ to $100 \%$ ).

\section{Results}

Twenty-five TA models and frameworks were analyzed for the scoping review. These are listed in the appendix. The models and frameworks were described in terms of program, organizational, or systems change in early childhood intervention, education, special education, health care, child welfare, pregnancy prevention, developmental disabilities, and youth development. Care was taken to be sure that the same model or framework was not described by different authors in different papers. In those cases where multiple papers included descriptions of the same model or framework, we included the one paper or report that had the most complete description of the TA model or framework.

\subsection{Core Elements}

The descriptions of the different tasks, activities, and practices in the TA models and frameworks together with those in Katz and Wandersman (2016) and Meyers et al. (2012) were used to define the core elements of TA as characterized by the model or framework developers. Table 1 shows the definitions and descriptions of the core 
Table 1. Core Elements of Technical Assistance (TA) Models and Frameworks

\begin{tabular}{l} 
Core Elements \\
\hline Preparation for Technical Assistance \\
1. Needs Assessment
\end{tabular}

1. Needs Assessment

2. Decision-Making

3. Visioning

4. Readiness for Change (Buy-in)

5. Organizational Capacity

Technical Assistance Plan

1. Goals and Objectives

2. Intervention Practices

3. Fit Assessment

4. Logic Model or Theory of Change

\section{TA Resources}

6. Staff Roles and Responsibilities

Technical Assistance Implementation

1. TA Provider Credibility

2. Professional Development

3. Coaching and Mentoring
Process for determining the gap between current conditions, practices, or outcomes and desired conditions, practices, or outcomes

Process for involving program staff in identifying, among alternatives, the options or priorities that best fit with the organization's mission or goals

Process for determining what an organization would do or "look like" if it was to make desired changes

Staff commitment to change program, organizational, or systems practices to improve effectiveness in order to achieve desired changes or outcomes

Ability of an organization to commit the human, program, and other resources needed for program, organization, or systems changes to produce desired practices

The immediate (objectives) and long-term (goals) program changes and outcomes that are the desired benefits of TA

The particular evidence-based intervention practice or best practices identified (targeted) to produce desired program, organizational, or systems change

Determining how well the targeted intervention practice matches (fits) the program or organization's mission, priorities, desired changes, staff beliefs, etc. and how well the proposed TA practices also fit the program ecology

A description or graphic representation of the relationship between desired program, organizational, or systems inputs and resources; the intervention practices, actions, or activities to affect desired change; and the intended outputs and outcomes of use of the practices, actions, or activities

TA resources made available to and/or provided to program staff to improve the use of targeted evidence-based or best practices

Specification of the roles and responsibilities of individual staff, and how enactment of those roles and responsibilities are expected to contribute to desired change

Practices used by a TA provider to establish staff trust, respect, rapport, and beliefs that the provider is acting in the best interests of the program and staff receiving TA

The evidence-based professional development practices used by a TA provider to build and strengthen staff, program, organization, and systems capacity to use targeted intervention practices

TA provider use of either or both coaching and mentoring as part of the provision of TA in interactions with staff to build and strengthen their capacity to use targeted intervention practices 
Table 1. continued

Core Elements

4. Consultation

5. TA Provider Support/Feedback

Technical Assistance Evaluation

1. Process Evaluation

2. Outcome Evaluation

3. Fidelity of Use of Intervention Practices

4. Fidelity of Use of TA Practices

5. Lessons Learned

Sustainability of TA-Facilitated Change

1. Capacity-Sustaining Activities

2. Continuous Quality Improvement

3. Ongoing TA Provider Support

4. Follow-Up TA Activities

\section{Definition of Terms}

Tailored responses to individual staff, groups of staff members, and other program staff in response to questions, concerns, etc. about staff adoption and use of targeted intervention practices

TA provider nonjudgmental acknowledgment, encouragement, and feedback on staff efforts toward and accomplishment of changing program practices consistent with the objectives and goals of the plan

Methods for determining if the practices, activities, or interventions specified (in a theory of change or logic model) were implemented as planned and resulted in identifiable outputs

Methods of determining if the practices, activities, or actions have resulted in desired changes and affect progress or benefits in the target group(s) of a program, organization, or system

Extent to which the key characteristics of targeted practices that are the focus of TA were implemented in a manner in which they were designed to be used or delivered

Extent to which the core elements of TA were used as intended and in a consistent manner with program staff responsible for use of the intervention practice constituting the focus of TA

Knowledge gained from the use of TA to promote staff use of the targeted intervention practice(s) constituting the focus of TA and the use of that information to make changes or improvements in the overall implementation of program activities

The program, organization, or systems resources, activities, and professional supports that are used to sustain or maintain the changes that have been put into place as a result of TA-related practices

Processes used to ensure ongoing improvements in a program, organization, or system that were the focus of TA

Procedures used to provide either or both informal and formal TA supports to program staff after the completion of TA-related activities

Planned activities used to provide program staff opportunities to share concerns and accomplishments and to obtain input, feedback, suggestions, etc. from a TA provider

TA elements that emerged from our review, analysis, and integration of the different TA models and frameworks. Our analysis identified five TA components and 25 TA core elements or practices.

\subsubsection{Preparation for Technical Assistance}

Five different core elements and practices were included in the TA models and frameworks to describe what TA providers do to engage key staff in preparing for the delivery of TA. This included a needs assessment or gap analysis of desired changes or improvements; staff decision-making to establish priorities for TA; staff visioning in terms of what a program, organization, or system would look like if desired changes were achieved; an assessment of staff readiness for and commitment to making desired changes; and determining if the program, organization, or 
system has the resources needed to make desired changes. Most TA model and framework developers described the same or similar combinations of these core elements as being important for planning the provision of TA.

\subsubsection{Technical Assistance Plan}

Six core elements were described as important for developing a TA plan. These included setting objectives and goals for program changes; specification of the evidence-based or innovative practices that would be the focus of TA; an assessment of whether the proposed intervention practice and TA approach "makes sense" and fits with the existing program mission and goals; the development of a logic model, theory of change, or other type of plan (e.g., Leeman et al., 2017) for describing the relationships between inputs, practices, and outcomes; the TA resources that will be made available by a TA provider to facilitate change; and the roles and responsibilities of staff in learning to use the targeted intervention practices to achieve desired program, organization, or system change. A TA plan was viewed by most model and framework developers as a necessary blueprint for ensuring staff had a clear understanding of what was to be done to achieve desired outcomes.

\subsubsection{Provision of Technical Assistance}

Five core elements were included in some but not all TA models and frameworks. These included explicit efforts to establish the credibility of the TA provider and the proposed approach to TA; the use of some type of professional development or training to promote staff abilities to use targeted practices; the use of coaching or mentoring by the TA provider as part of professional development; TA provider consultation in response to staff requests for assistance and guidance; and TA provider supports and performance feedback in response to progress toward using targeted intervention practices. Although nearly all TA model and framework developers noted the importance of TA provider professional development, there was very little consensus in terms of the types of professional development that should be used, and not a single model or framework included a description of or reference to evidence-based adult learning or professional development (Dunst, Bruder, \& Hamby, 2015; Dunst, Trivette, \& Hamby, 2010) as important for capacity-building purposes.

\subsubsection{Technical Assistance Evaluation}

Four core evaluation practices were described by most TA model and framework developers. The least mentioned core element was fidelity of use of TA practices. This core element is included because there is now evidence that the fidelity of the use of TA professional development practices is related to the fidelity of staff use of targeted intervention practices (Dunst, Trivette, \& Raab, 2013; Fixsen et al., 2005). Most models and frameworks included the description of process or formative evaluation; outcome or summative evaluation; fidelity of use of the targeted intervention practice; and, to a lesser degree, the use of lessons learned from the provision and evaluation of TA to inform improvements in program, organization, and systems change activities and practices. The latter is important because using lessons learned to inform improvements in the provision of TA is an important factor contributing to desired TA outcomes (Hamilton, Shanley, Dailey, \& McInerney, 2003; Lyons, Hoag, Orfield, \& Streeter, 2016).

\subsubsection{Sustainability of TA-Facilitated Change}

The sustainability of TA provider facilitated program, organization, or system change is considered by a number of TA experts as a necessary activity if changes are to be maintained after the completion of formal TA (Hodge \& Turner, 2016; McIntosh, Horner, \& Sugai, 2009; Vaughn, Klingner, \& Hughes, 2000). Most models and frameworks include descriptions of activities to ensure or at least increase the likelihood that changes are sustained. This is often done in terms of a continuous quality improvement plan that includes ongoing training provided by designated program or organization staff. Some models and frameworks include descriptions of the availability of ongoing TA-provider supports after the completion of formal TA activities typically delivered by phone consultations, email communication, and other electronic means. In some cases, planned follow-up TA activities were included to provide support and guidance after staff has had some time to implement targeted interventions where TA follow-up activities could focus on program, organization, or systems-related issues.

\subsection{Scope of TA Core Elements}

Table 2 shows the number and percent of TA models and frameworks that included each of the 25 core elements. The core elements mentioned most frequently were needs assessment $(96 \%)$, objectives and goals (92\%), professional development (88\%), targeted intervention practices $(84 \%)$, TA resources $(80 \%)$, TA provider feedback $(80 \%)$, and process evaluation $(80 \%)$. The core elements mentioned least often were establishing TA provider credibility (16\%), fidelity of the use of capacity-building TA practices (28\%), fit assessment (40\%), and follow-up TA activities $(40 \%)$. 
A comparison of our findings with those reported by Katz and Wandersman (2016) and Meyers et al. (2012) indicates that the percent of core elements in the TA models and frameworks is higher than that reported by these investigators for the same or very similar TA practices. For example, Katz and Wandersman (2016) and Meyers et al. (2012) found that needs assessment was mentioned, respectively, by $66 \%$ and $56 \%$ of the investigators of the reports included in their analyses, whereas we found that $96 \%$ of TA models and frameworks included needs assessment as a core element. This was not surprising since the TA model and framework developers specifically intended to describe the practice that are the core elements of their models and frameworks.

The extent to which the different TA models and frameworks included combinations of core elements and practices in each of the five TA components is shown in Figure 1. What is shown is the percent of core elements in each TA model and framework in each component averaged across the 25 TA papers and reports.

Table 2. Core Elements and Practices Included in the Descriptions of the Technical Assistance Models and Frameworks

\begin{tabular}{lcc}
\hline Core Elements & Number & Percent \\
\hline Preparation for Technical Assistance & & \\
Needs Assessment & 24 & 96 \\
Decision-Making & 16 & 64 \\
Visioning & 17 & 68 \\
Readiness for Change & 19 & 76 \\
Organizational Capacity & 15 & 60 \\
Technical Assistance Plan & & \\
Goals and Objectives & 23 & 92 \\
Intervention Practices & 21 & 84 \\
Fit Assessment & 10 & 40 \\
Logic Model or Theory of Change & 12 & 48 \\
Technical Assistance Provided Resources & 20 & 80 \\
Staff Roles and Responsibilities & 13 & 52 \\
Technical Assistance Implementation & & \\
Technical Assistance Provider Credibility & 4 & 16 \\
Professional Development & 22 & 88 \\
Coaching and Mentoring & 13 & 52 \\
Technical Assistance Provider Consultation & 20 & 60 \\
Technical Assistance Provider Support/Feedback & 15 & 80 \\
Technical Assistance Evaluation & & \\
Process Evaluation & 20 & 80 \\
Outcome Evaluation & 15 & 60 \\
Intervention Practice Fidelity & 10 & 40 \\
Technical Assistance Practice Fidelity & 7 & 28 \\
Lessons Learned & 11 & 44 \\
Sustainability & & 64 \\
Capacity-Sustaining Activities & 16 & 60 \\
Continuous Quality Improvement & 15 & 48 \\
Ongoing Technical Assistance Provider Supports & 12 & 40 \\
$\quad$ Follow-Up Technical Assistance Activities & 10 &
\end{tabular}

The average percent of core elements differed as evidenced by a between component repeated measures analysis-of-variance, $F(4,21)=4.92, p=.006$. As is clearly shown in Figure 1, there are discernable differences in the percent of core elements included in each component, ranging between 53\% (sustainability) and $73 \%$ (preparation).

The mean difference effect sizes for each of the between component comparisons are shown in Table 3 . These were computed using a standard effect size calculator for within group (paired $t$-test) mean difference scores adjusted for the correlations between the individual component scores (Faul, Erdfelder, Lang, \& Buchner, 2007). The sizes of 
effects for 9 of the 10 between component comparisons are small to medium, and may be taken as evidence for the differential importance of the core TA elements as described by the TA model and framework developers.

Although an assessment of why this would be the case was beyond the purpose of our review, there are at least two factors that may be at play. One is the fact that the TA models and frameworks differed in terms of those that "offered" primarily predetermined practices as the focus of TA (e.g., Algozzine et al., 2010; Goreczny, Hobbs, Peterson, Bosse, \& Perrell, 2015) whereas others were entirely based on program, organization, and systems-level staff identified practices as the focus of TA (e.g., Butterfoss, 2004; Le, Anthony, Bronheim, Holland, \& Perry, 2014). A second and not so apparent factor is the underlying purpose of TA. On the one hand, some TA model and framework developers focused primarily on program, organization, or system capacity-building with little or no emphasis on the sustainability of TA-facilitated change (e.g., Otoo, Agapitova, \& Behrens, 2009; Soler, Cocozza, \& Henry, 2013). On the other hand, some TA model and framework developers focused on specific aspects of TA but not other core elements (e.g., Fischer, Ellingson, McCormick, \& Sinkowitz-Cochran, 2014; Luiselli \& Luiselli, 1995). It is possible that those differences account for at least some of the variability in the particular core elements that are viewed as most and least important.

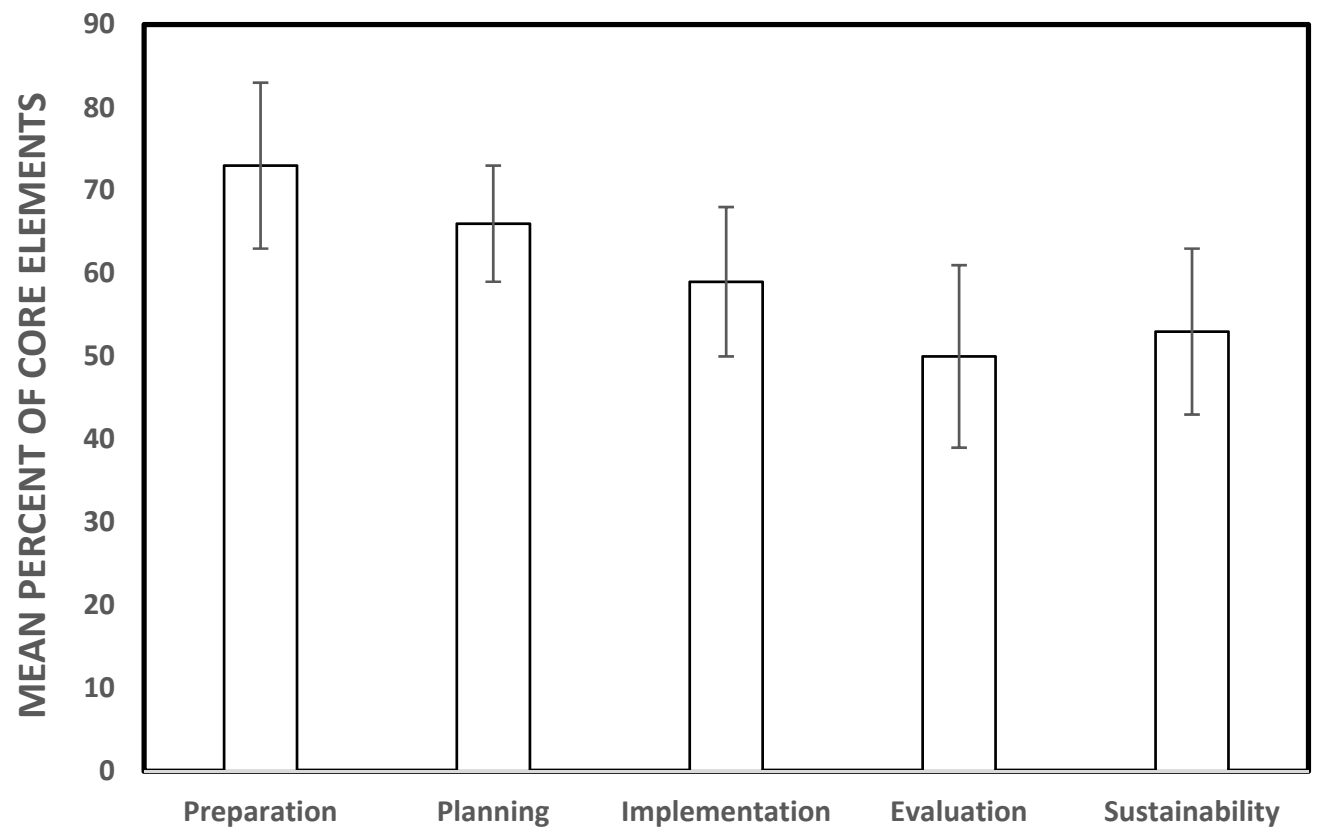

TECHNICAL ASSISTANCE COMPONENTS

Figure 1. Mean Percent of Core Elements Included in Each Technical Assistance Model and Framework Component and the $95 \%$ Confidence Intervals for the Average Scores

Table 3. Between Technical Assistance Component Mean Difference Effect Sizes for the Percent of Core Elements Included in Each Component

\begin{tabular}{|c|c|c|c|c|c|}
\hline \multirow[b]{2}{*}{ TA Components } & \multicolumn{5}{|c|}{ TA Components } \\
\hline & PTA & TAP & TAI & TAE & STA \\
\hline Preparation for Technical Assistance (PTA) & - & .28 & .40 & .72 & .56 \\
\hline Technical Assistance Planning (TAP) & & - & 28 & .61 & .40 \\
\hline Technical Assistance Implementation (TAI) & & & - & .25 & .17 \\
\hline Technical Assistance Evaluation (TAE) & & & & - & .06 \\
\hline Sustainability of Technical Assistance (STA) & & & & & - \\
\hline
\end{tabular}




\section{Discussion}

The scoping review proved informative in terms of identifying generally agreed upon core elements of TA. The core elements, taken together, provide evidence for the make-up of TA models and practices and the particular core elements that ought to be considered as part of planning, delivering, and evaluating TA. Notwithstanding the differential inclusion of core elements in the five TA components, there was relative consistency in the particular types of TA practices that were considered most important.

This scoping review differed from other reviews of TA (Katz \& Wandersman, 2016) and TA-related (Bertram et al., 2011; Meyers et al., 2012; Wandersman et al., 2012) practices by focusing specifically on identifying the core elements of existing TA models and frameworks rather than focusing on model building in order to identify the practices (Katz \& Wandersman, 2016), critical steps (Meyers et al., 2012), or core components (Bertram et al., 2011) as part of the evaluation of research on the effectiveness of TA. This is most likely the reason that the percent of TA models and frameworks in our review included specific core elements that were reported more often than in other reviews.

\subsection{Implications for Research}

The core TA elements identified in the scoping review are currently being used to code the use of the practices in studies and evaluations of TA interventions to determine if the use of the TA practices is differentially related to changes or improvements in program, organization, or system practices as well as changes in other outcomes. West et al. (2012) concluded based on their review of the effectiveness of TA that "our assessment of published evaluations found limited evidence for its effectiveness" (p . 915). Those investigators, however, did not evaluate the relationships between TA core elements or practices and study outcomes, and therefore their conclusion may not accurately reflect factors associated with TA outcomes.

Hodge et al. (2016), as part of a narrative review of TA-related practices, concluded that the particular practices constituting the focus of our scoping review were major factors associated with program, organization, or system change. These investigators as well made no attempt to relate those factors to outcomes of interest in a way that identifies practice-outcome relationships. The extent to which the latter could be ascertained in a quantitative analysis of TA core component-study outcome relationships is currently the focus of our research on which core elements and combinations of elements are associated with observed or reported changes in program, organization, and system practices. The results are expected to inform the identification of the particular core elements that matter most in terms of research and evaluation study outcomes.

\section{Conclusion}

Despite a lack of a generally agreed upon definition of TA, there is some agreement in terms of at least a dozen or so Core TA elements. Whether these core elements, or infrequently mentioned core elements such as the fidelity of TA practices, are more important than others necessitates core element-outcome studies and reviews to identify what matters most in terms of explaining how and in what manner TA is effective in terms of influencing program organization, or system changes. The interested reader is referred to Dunst el al. (in press) for a review of these types of studies where specific core elements and combinations of core elements were related to the largest sizes of effects of TA practices.

\section{Acknowledgments}

The preparation of this paper was supported, in part, by funding from the U.S. Department of Education, Office of Special Education Programs (No. 325B120004) for the Early Childhood Personnel Center, University of Connecticut Health Center (Mary Beth Bruder, Principal Investigator). The contents and opinions expressed, however, are those of the authors and do not necessarily reflect the policy or official position of the U.S. Department of Education, Office of Special Education Programs, University of Connecticut Health Center, or the Early Childhood Personnel Center, and no endorsement should be inferred or implied.

\section{References}

Algozzine, B., Horner, R. H., Sugai, G., Dickey, C. R., Eber, L., Kincaid, D., . . . Tobin, T. (2010). Evaluation blueprint for school-wide positive behavior support. Retrieved from https://www.pbisapps.org/Resources/SWIS\%20Publications/Evaluation\%20Blueprint\%20for\%20School-Wide \%20Positive\%20Behavior\%20Support.pdf 
Bertram, R. M., Suter, J. C., Bruns, E. J., \& O'Rourke, K. E. (2011). Implementation research and wraparound literature: Building a research agenda. Journal of Child and Family Studies, 20, 713-725. https://doi.org/10.1007/s10826-010-9430-3

Blase, K. A. (2009). Technical assistance to promote service and system change. Roadmap to Effective Intervention Practices, 4, 1-15.

Butterfoss, F. D. (2004). The coalition technical assistance and training framework: Helping community coalitions help themselves. Health Promotion Practice, 5(2), 118-126. https://doi.org/10.1177/1524839903257262

Chapman, D. W., \& Moore, A. S. (2010). A meta-look at meta-studies of the effectiveness of development assistance to education. International Review of Education, 56(5/6), 547-565. https://doi.org/10.1007/s11159-011-9185-0

Dunst, C. J., Annas, K., Wilkie, H., \& Hamby, D. W. (in press). Review of the effects of technical assistance on program, organization, and system change. International Journal of Evaluation and Research in Education, 8(2). https://doi.org/10.11591/ijere.v8i2.17978

Dunst, C. J., Bruder, M. B., \& Hamby, D. W. (2015). Metasynthesis of in-service professional development research: Features associated with positive educator and student outcomes Educational Research and Reviews, 10(12), 1731-1744. https://doi.org/10.5897/ERR2015.2306

Dunst, C. J., Trivette, C. M., \& Hamby, D. W. (2010). Meta-analysis of the effectiveness of four adult learning methods and strategies. International Journal of Continuing Education and Lifelong Learning, 3(1), 91-112.

Dunst, C. J., Trivette, C. M., \& Raab, M. (2013). An implementation science framework for conceptualizing and operationalizing fidelity in early childhood intervention studies. Journal of Early Intervention, 35(2), 85-101. https://doi.org/10.1177/1053815113502235

Faul, F., Erdfelder, E., Lang, A.-G., \& Buchner, A. (2007). G*Power 3: A flexible statistical power analysis program for the social, behavioral, and biomedical sciences. Behavior Research Methods, 39, 175-191. https://doi.org/10.3758/BF03193146

Fischer, L., Ellingson, K., McCormick, K., \& Sinkowitz-Cochran, R. (2014). The role of the public health analyst in the delivery of technical assistance to state health departments for healthcare-associated infection prevention. Medical Care, 52(2 Suppl. 1). https://doi.org/10.1097/MLR.0000000000000055

Fixsen, D. L., \& Blase, K. A. (2009). Technical assistance in special education past, present and future. Topics Early Childhood Special Education, 29(1), 62-64. https://doi.org/10.1177/0271121409333795

Fixsen, D. L., Naoom, S. F., Blase, K. A., Friedman, R. M., \& Wallace, F. (2005). Implementation research: A synthesis of the literature. Chapel Hill, NC: University of North Carolina. Retrieved from https://fpg.unc.edu/node/4445.

$\begin{array}{lllll}\text { Free Dictionary. } & \text { (2018). } & \text { Technical } & \text { assistance. } & \text { Retrieved }\end{array}$ https://www.thefreedictionary.com/technical+assistance.

Friesen, C., Fetterman, M., Barclay, J., \& Burns, J. (2017). Taking steps to healthy success: What level of training and technical assistance is associated with the greatest adoptation of nutrition and physical activity "Best Practices" in the child care setting? Journal of the Academy of Nutrition and Dietetics, 117 Suppl l-Abstracts(9), A-64. https://doi.org/10.1016/j.jand.2017.06.197

Godfrey, M., Sophal, C., Kato, T., Piseth, L. V., Dorina, P., Saravy, T., . . . Sovannarith, S. (2002). Technical assistance and capacity development in an aid-dependent economy: The experience of Cambodia. World Development, 30(3), 355-373. https://doi.org/10.1016/S0305-750X(01)00121-8

Goreczny, A. J., Hobbs, E. R., Peterson, L. M., Bosse, R. M., \& Perrell, C. J. (2015). Improving quality of care for individuals with intellectual and developmental disabilities via consultation: Process improvement and support of interprofessional teams. Review Joumal of Autism and Developmental Disorders, 2(1), 19-25. https://doi.org/10.1007/s40489-014-0031-8

Gutin, S. A., Amico, K. R., \& Hunguana, E. (2017). The relationship of repeated technical assistance support visits to the delivery of positive health, dignity, and prevention (PHDP) messages by healthcare providers in Mozambique: A longitudinal multilevel analysis. Journal of the International Association of Providers of AIDS Care (JIAPAC), 16(5), 487-493. https://doi.org/10.1177/2325957417724206

Hamilton, J. L., Shanley, J., Dailey, D., \& McInerney, M. (2003). Providing technical assistance to local school 
districts: Lessons Learned: American Institutes for Research.

Hodge, L. M., \& Turner, K. M. T. (2016). Sustained implementation of evidence-based programs in disadvantaged communities: A conceptual framework of supporting factors. American Journal of Community Psychology, 58(1/2), 192-210. https://doi.org/10.1002/ajcp.12082

Hunter, S. B., Chinman, M., Ebener, P., Imm, P., Wandersman, A., \& Ryan, G. W. (2009). Technical assistance as a prevention capacity-building tool: A demonstration using the Getting To Outcomes ${ }^{\circledR}$ Framework. Health Education \& Behavior, 36(5), 810-828. https://doi.org/10.1177/1090198108329999

Katz, J., \& Wandersman, A. (2016). Technical assistance to enhance prevention capacity: A research syntheses of the evidence base. Prevention Science, 17, 417-428. https://doi.org/10.1007/s11121-016-0636-5

Le, L. T., Anthony, B. J., Bronheim, S. M., Holland, C. M., \& Perry, D. F. (2014). A technical assistance model for guiding service and systems change. Journal of Behavioral Health Services \& Research, 43(3), 1-15. https://doi.org/10.1007/s11414-014-9439-2

Leeman, J., Calancie, L., Kegler, M. C., Escoffery, C. T., Herrmann, A. K., Thatcher, E., . . Fernandez, M. (2017). Developing theory to guide building practitioners' capacity to implement evidence-based interventions. Health Education \& Behavior, 44(1), 59-69. https://doi.org/10.1177/1090198115610572

Luiselli, T. E., \& Luiselli, J. K. (1995). Inclusive education of young children with deaf-blindness: A technical assistance model. Journal of Visual Impairment \& Blindness, 89(3), 249-257.

Lyons, J., Hoag, S. D., Orfield, C., \& Streeter, S. (2016). Designing technical-assistance programs: Considerations for funders and lessons learned. The Foundation Review, 8(5), 68-78. https://doi.org/10.9707/1944-5660.1342

McInerney, M., \& Hamilton, J. L. (2007). Elementary and middle schools technical assistance center: An approach to support the effective implementation of scientifically based practices in special education. Exceptional Children, 73, 242-255. https://doi.org/10.1177/001440290707300207

McIntosh, K., Horner, R. H., \& Sugai, G. (2009). Sustainability of systems-level evidence-based practices in schools: Knowledge and future directions. In W. Sailor, G. Dunlop, G. Sugai, \& R. Horner (Eds.), Handbook of positive behavior support (pp. 327-352). New York, NY: Springer.

Meyers, D. C., Durlak, J. A., \& Wandersman, A. (2012). The quality implementation framework: A synthesis of critical steps in the implementation process. American Journal of Community Psychology, 50(3-4), 462-480. https://doi.org/10.1007/s10464-012-9522-x

Olson, J. R. (2018). A formative evaluation of a coach-based technical assistance model for youth- and family-focused programming. Evaluation and Program Planning, 67, 29-37. https://doi.org/10.1016/j.evalprogplan.2017.11.002

Otoo, S., Agapitova, N., \& Behrens, J. (2009). The capacity development results framework: A strategic and results-oriented approach to learning for capacity development. Retrieved from http://siteresources.worldbank.org/CSO/Resources/228716-1369241545034/The_Capacity_Development_Resul ts_Framework.pdf

Paulsell, D., Del Grosso, P., \& Supplee, L. (2014). Supporting replication and scale-up of evidence-based home visiting programs: Assessing the implementation knowledge base. American Journal of Public Health, 104(9), 1624-1632. https://doi.org/10.2105/AJPH.2014.301962

Pham, M. T., Rajić, A., Greig, J. D., Sargeant, J. M., Papadopoulos, A., \& McEwen, S. A. (2014). A scoping review of scoping reviews: Advancing the approach and enhancing the consistency. Research Synthesis Methods, 5(4), 371-385. https://doi.org/10.1002/jrsm.1123

Ray, M. L., Wilson, M. M., Wandersman, A., Meyers, D. C., \& Katz, J. (2012). Using a training-of-trainers approach and proactive technical assistance to bringing evidence based programs to scale: An operationalization of the interactive systems framework's support system. American Journal of Community Psychology, 50(3-4), 415-427. https://doi.org/10.1007/s10464-012-9526-6

Soler, M. I., Cocozza, J. J., \& Henry, A. (2013). Providing and receiving technical assistance: Lessons from models for change. Retrieved from http://strengtheningnonprofits.org/resources/guidebooks/Delivering_Training_and_Technical_Assistance.pdf

Sugai, G., Simonsen, B., Freeman, J., \& La Salle, T. (2016). Capacity development and multi-tiered systems of 
support: Guiding principles. Australasian Journal of Early Childhood, 40(2), 80-98. https://doi.org/10.1017/jse.2016.11

Tricco, A. C., Lillie, E., Zarin, W., O'Brien, K., Colquhoun, H., Kastner, M., . . . Straus, S. E. (2016). A scoping review on the conduct and reporting of scoping reviews. BMC Medical Research Methodology, 16(15), 1-10. https://doi.org/10.1186/s12874-016-011 6-4

Vaughn, S., Klingner, J., \& Hughes, M. (2000). Sustainability of research-based practices. Exceptional Children, 66, 163-171. https://doi.org/10.1177/001440290006600202

Wandersman, A., Chien, V. H., \& Katz, J. (2012). Toward an evidence-based system for innovation support for implementing innovations with quality: Tools, training, technical assistance, and quality assurance/quality improvement. American Journal of Community Psychology, 50(3-4), 445-459. https://doi.org/10.1007/s10464-012-9509-7

West, G. R., Clapp, S. P., Davidson Averill, E. M., \& Cates, W., Jr. (2012). Defining and assessing evidence for the effectiveness of technical assistance in furthering global health. Global Public Health, 7(9), 915-930. https://doi.org/10.1080/17441692.2012.682075

Yousafzai, A. K., Rasheed, M. A., Daelmans, B., Manji, S., Arnold, C., Lingam, R., . . Lucas, J. E. (2014). Capacity building in the health sector to improve care for child nutrition and development. Annals of the New York Academy of Sciences, 1308, 172-182. https://doi.org/10.1111/nyas.12322

Appendix

\section{Technical Assistance Models and Frameworks}

Algozzine, B., Horner, R. H., Sugai, G., Dickey, C. R., Eber, L., Kincaid, D., . . . Tobin, T. (2010). Evaluation blueprint for school-wide positive behavior support Retrieved from https://www.pbisapps.org/Resources/SWIS\%20Publications/Evaluation\%20Blueprint\%20for\%20School-Wide \%20Positive\%20Behavior\%20Support.pdf

ASAPconnect. (2012). A framework for effective technical assistance delivery, Vol. 2: What is effective technical assistance delivery? Retrieved from https://www.issuelab.org/resource/after-school-technical-assistance-providers-evaluation-framework.html

Barrett, S., Boezio, C., Horner, R., \& Sugai, G. (2006, July). Sustaining and expanding effective practices: Lessons learned from implementation of school-wide positive behavior supports, Presentation made at the U.S. Department of Education, Office of Special Education Programs, Project Directors' meeting, Washington, DC. Retrieved from https://slideplayer.com/slide/8681608/.

Boucher, J., \& Roch, J. M. (2017). Absorptive capacity: North-south partnerships and organizational learning within development networks. European Journal of Development Research, 29(2), 404-422. https://doi.org/10.1057/s41287-016-0005-z

Butterfoss, F. D. (2004). The coalition technical assistance and training framework: Helping community coalitions help themselves. Health Promotion Practice, 5(2), 118-126. https://doi.org/10.1177/1524839903257262

Chaple, M., Sacks, S., Randell, J., \& Kang, B. (2016). A technical assistance framework to facilitate the delivery of integrated behavioral health services in federally qualified health centers (FQHCs). Journal of Substance Abuse Treatment, 60, 62-69. https://doi.org/10.1016/j.jsat.2015.08.006

Chinman, M., Imm, P., \& Wandersman, A. (2004). Getting to outcomes 2004: Promoting accountability through methods and tools for planning, implementation, and evaluation Retrieved from https://www.rand.org/pubs/technical_reports/TR101.html

Clark, N. M., Cushing, L. S., \& Kennedy, C. H. (2004). An intensive onsite technical assistance model to promote inclusive educational practices for students with disabilities in middle school and high school. Research \& Practice for Persons with Severe Disabilities, 29(4), 253-262. https://doi.org/10.2511/rpsd.29.4.253

Domitrovich, C. E., Bradshaw, C. P., Poduska, J. M., Hoagwood, K. E., Buckley, J. A., Olin, S. S., . . Ialongo, N. (2008). Maximizing the implementation quality of evidence-based preventive interventions in schools: A conceptual framework. Advances in School Mental Health Promotion, 1(3), 6-28. https://doi.org/10.1080/1754730X.2008.9715730 
Fischer, L., Ellingson, K., McCormick, K., \& Sinkowitz-Cochran, R. (2014). The role of the public health analyst in the delivery of technical assistance to state health departments for healthcare-associated infection prevention. Medical Care, 52(2 Suppl. 1).

Goreczny, A. J., Hobbs, E. R., Peterson, L. M., Bosse, R. M., \& Perrell, C. J. (2015). Improving quality of care for individuals with intellectual and developmental disabilities via consultation: Process improvement and support of interprofessional teams. Review Joumal of Autism and Developmental Disorders, 2(1). https://doi.org/10.1007/s40489-014-0031-8

Kahn, L., Hurth, J., Kasprzak, C. M., Diefendorf, M. J., Goode, S. E., \& Ringwalt, S. S. (2009). The national early childhood technical assistance center model for long-term systems change. Topics in Early Childhood Special Education, 29(1), 24-39. https://doi.org/10.1177/0271121409334039

Le, L. T., Anthony, B. J., Bronheim, S. M., Holland, C. M., \& Perry, D. F. (2014). A technical assistance model for guiding service and systems change. Journal of Behavioral Health Services \& Research, 43(3), 1-15. https://doi.org/10.1007/s11414-014-9439-2

Livet, M., Courser, M., \& Wandersman, A. (2008). The Prevention Delivery System: Organizational context and use of comprehensive programming frameworks. American Journal of Community Psychology, 41, 361-378. https://doi.org/10.1007/s10464-008-9164-1

Luiselli, T. E., \& Luiselli, J. K. (1995). Inclusive education of young children with deaf-blindness: A technical assistance model. Journal of Visual Impairment \& Blindness, 89(3), 249-257.

Lyons, J., Hoag, S. D., Orfield, C., \& Streeter, S. (2016). Designing technical-assistance programs: Considerations for funders and lessons learned. The Foundation Review, 8(5), 68-78. https://doi.org/10.9707/1944-5660.1342

McCart, A., McSheehan, M., \& Sailor, W. (2015). Differential technical assistance for sustainable transformation SWIFT Center Technical Assistance Brief \#2 Retrieved from http://www.swiftschools.org/sites/default/files/SWIFT\%20Differentiated\%20Technical\%20Assistance\%20.pdf

National Center on Child Care Professional Development Systems and Workforce Initiatives (PDW Center). (2013). Technical assistance planning and implementation guide. Washington, DC: ACF's Office of Child Care and Office of Head Start. from https://childcareta.acf.hhs.gov/sites/default/files/public/20130520_rev_pdwcenter_ta_guide_508.pdf.

Otoo, S., Agapitova, N., \& Behrens, J. (2009). The capacity development results framework: A strategic and results-oriented approach to learning for capacity development. Retrieved from http://siteresources.worldbank.org/CSO/Resources/228716-1369241545034/The_Capacity_Development_Resul ts_Framework.pdf

Palsha, S. A., \& Wesley, P. W. (1998). Improving quality in early childhood environments through on-site consultation. Topics in Early Childhood Special Education, 18(4), 243-253. https://doi.org/10.1177/027112149801800407

Ray, M. L., Wilson, M. M., Wandersman, A., Meyers, D. C., \& Katz, J. (2012). Using a training-of-trainers approach and proactive technical assistance to bringing evidence based programs to scale: An operationalization of the interactive systems framework's support system. American Journal of Community Psychology, 50(3-4), 415-427. https://doi.org/10.1007/s10464-012-9526-6

Reyes, E. M., Sharma, A., Thomas, K. K., Kuehn, C., \& Morales, J. R. (2014). Development of a technical assistance framework for building organizational capacity of health programs in resource-limited settings. BMC Health Services Research, 14, 399-410. Retrieved from https://bmchealthservres.biomedcentral.com/track/pdf/10.1186/1472-6963-14-399 https://doi.org/10.1186/1472-6963-14-399

Soler, M. I., Cocozza, J. J., \& Henry, A. (2013). Providing and receiving technical assistance: Lessons from models for change. Retrieved from http://strengtheningnonprofits.org/resources/guidebooks/Delivering_Training_and_Technical_Assistance.pdf

Sugai, G., Simonsen, B., Freeman, J., \& La Salle, T. (2016). Capacity development and multi-tiered systems of support: Guiding principles. Australasian Journal of Early Childhood, 40(2), 80-98. https://doi.org/10.1017/jse.2016.11

USAID. (2011). Organizational capacity-building framework: A foundation for stronger, more sustainable 
HIV/AIDS programs, organizations \& networks. Technical Brief No. 2. Washington, DC: USAID AIDS Support and Technical Assistance Resources \& AIDSTAR-Two. 